\title{
Comparison of the performances of two asynchronous generators used in wind energy conversion
}

\author{
Aicha Wahabi \\ Energy and electrical systems laboratory \\ National High School of Electricity and Mechanics, Hassan II University, Casablanca,MOROCCO \\ Fatima Ezzahra Bounifli \\ Energy and electrical systems laboratory \\ National High School of Electricity and Mechanics, Hassan II University, Casablanca, MOROCCO \\ Abdelhadi Elmoudden \\ Energy and electrical systems laboratory \\ National High School of Electricity and Mechanics, Hassan II University, Casablanca, MOROCCO
}

\begin{abstract}
The objective of this work is to compare the performance of two asynchronous generators in the wind energy conversion. A study of the two energy conversion chains will be carried out to evaluate the two structures and to make an optimal choice of the system at a better yield and at a lower cost.

We will begin this discussion with a description of a wind energy conversion chain. We are interested in the modelling and simulation of a turbine with a speed multiplier, and the asynchronous generator. The adopted technique is developed under the Matlab / Simulink / SimPowerSystems environment. The simulation results are presented and analysed at the end of this work.
\end{abstract}

Keywords - Wind chain, Turbine, Asynchronous machine, Converter, Modeling, Matlab / Simulink.

\section{INTRODUCTION}

In recent years, wind systems have received increased attention. Asynchronous generators are widely used in power generation systems, their advantages are simple construction (without brushes), robustness and low maintenance cost [1]. Wind systems can be used in standalone mode or connected to the grid.

Today, two types of wind turbines connected to the electricity grid can be identified: fixed speed wind turbines, usually with an asynchronous squirrel cage machine. The second type is a variable speed wind turbine with, in general, a doubly-feed induction generator (DFIG) or a synchronous machine with a permanent magnet (SMPM). The latter (SMPM or DFIG), which have large adjustment capabilities, are mainly used for centralized production.

Current wind turbines are very sophisticated machines taking advantage of aerodynamic improvements in mechanical structure and electrical control, they are capable of producing several megawatts of electrical energy. It should be noted that with the development of power electronics, doubly-feed induction generators are increasingly used for the production of high power.

\section{MODELING OF THE DIFFERENT ELEMENTS OF THE WIND CHAIN}

Description of a System of Wind Energy Conversion-

In general the chain contains the wind turbine, the multiplier, the transformer and the load 


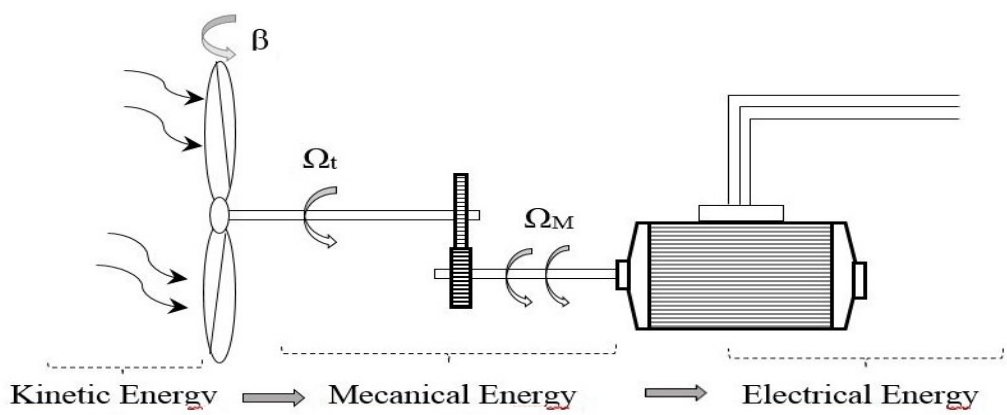

Figure 1: Schematic diagram of a wind energy conversion chain

\section{A. Modeling and Simulation of the Turbine-}

By applying the theory of the momentum and the Bernoulli theorem, we can determine the incident power (the theoretical power), due to the wind [3] [4] [5]:

$$
\mathrm{P}_{\text {incident }}=\frac{1}{2} \mathrm{p} \cdot \mathrm{S} \cdot \mathrm{v}^{\mathrm{a}}
$$

$\mathrm{S}$ : The surface swept by the blades of the turbine $\left[\mathrm{m}^{2}\right]$;

$\rho$ : The density of air $(\rho=1225 \mathrm{~kg} / \mathrm{m} 3$ at atmospheric pressure);

v : Wind speed $[\mathrm{m} / \mathrm{s}]$.

In a turbine, the power extracted from provided on the rotor of the turbine is lower than the incident power.

$$
P_{\text {ext. }}=\frac{1}{2} \rho \cdot S \cdot C_{p}(\lambda, \beta) \cdot v^{a}
$$

$C_{p}\left(\lambda_{s} \beta\right):$ is the power coefficient which expresses the efficiency of the turbine, it depends on the ratio $\lambda$, this ratio represents the ratio of the turbine speed at the end of the blades and the wind speed, and the orientation angle $\beta$.

$$
\lambda=\frac{\mathrm{Rn}_{\mathrm{t}}}{\mathrm{Y}}
$$

The maximum power coefficient $\mathbf{C}_{\mathrm{p}}$ was determined by Albert Betz (1920) as follows:

$$
C_{\mathrm{p}}^{\max }(\lambda, \beta)=\frac{16}{27} \approx 0,593
$$

This coefficient depends on the constitution of the turbine, for a wind medium power we have:

$$
c_{p}\left(\lambda_{1} \beta\right)=c_{1},\left(c_{2}, \frac{1}{A}-c_{20} \beta-c_{4}\right), e^{-c_{5} \frac{1}{A}}+c_{6}, \lambda
$$

Note that although the path checks the Betz limit is based on the expression (6):

$$
C_{\mathrm{p}}^{\max }(\lambda, \beta)=\frac{16}{27} \approx 0,593
$$

Also, we can say that this turbine will present its maximum efficiency for a speed ratio $\lambda$ [3] [4] [5],of the order of 23 since in general, $c_{p}$ is maximal for $\beta=0$

$\mathrm{G}_{\mathrm{t}}$ is the torque on the slow axis at the turbine :

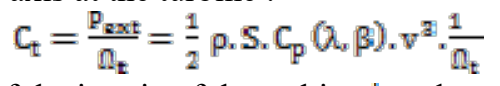

The total inertia $j$ consists of the inertia of the turbine $j_{t}$ reduced the fast axis and the inertia of the generator $j_{E}$ :

$$
\mathrm{j}=\frac{\mathrm{j}_{\mathrm{t}}}{\mathrm{G}^{2}}+\mathrm{j}_{\mathrm{g}}
$$

The fundamental equation of dynamics can be written:

$$
\mathrm{j} \frac{\mathrm{d} \mathrm{\Lambda}_{\mathrm{Mec}}}{\mathrm{dt}}=\mathrm{C}_{\mathrm{M}}=\mathrm{C}_{\mathrm{t}}-\mathrm{C}_{\mathrm{em}}-\mathrm{fn}_{\mathrm{Mec}}
$$

In order to subtract the maximum power of the incident energy, must continuously adjust the speed of rotation of the turbine to the wind: 


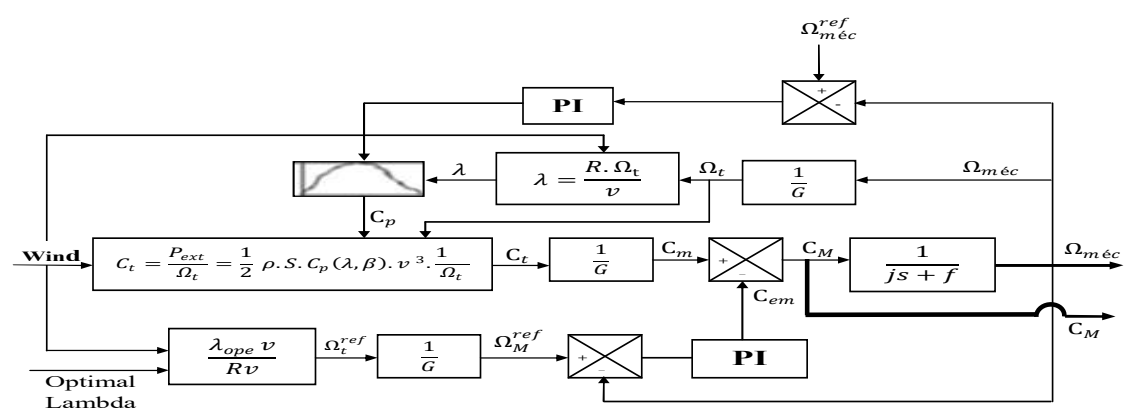

Figure 2: Schematic diagram of the turbine with Proportional-Integral (PI) controllers

\section{B. Modlling of the asynchronous generator-}

The model of asynchronous squirrel cage machine:

For the 3-phase stator, this writing is summarized by the following condensed matrix [1], [7]:

$$
\left[\mathrm{V}_{\text {sabc }}\right]=\left[\mathrm{R}_{g}\right] *\left[\mathrm{i}_{\text {sabs }}\right]+\frac{\mathrm{d}}{\mathrm{dt}}\left[\emptyset_{\text {sabc }}\right]
$$

With [ $\left.\mathrm{V}_{\mathrm{sg}}\right]$ : three-phase stator voltage of the asynchronous machine.

[Rs]: Resistance of stator phase.

[i $\left.i_{\text {sabs }}\right]$ : Three-phase stator current of the asynchronous machine.

$\left[\sigma_{3 \mathrm{Bg}}\right]$ : Feed-phase stator of the synchronous machine.

$$
\left[\mathrm{V}_{\mathrm{rabc}}\right]=\left[\mathrm{R}_{\mathrm{r}}\right] *\left[\mathrm{i}_{\mathrm{rabs}}\right]+\frac{\mathrm{d}}{\mathrm{dt}}\left[\emptyset_{\mathrm{rabc}}\right]=0
$$

With [ $\left.V_{\mathrm{rabc}}\right]$ : three-phase rotor voltage of the asynchronous machine.

$\left[R_{r}\right]$ : Resistance of rotor phase.

[1 ${ }_{\text {rabs }}$ ]: Three-phase rotor current of the asynchronous machine.

$\left[\emptyset_{\mathrm{rabe}}\right]$ Feed-phase rotor of the synchronous machine.

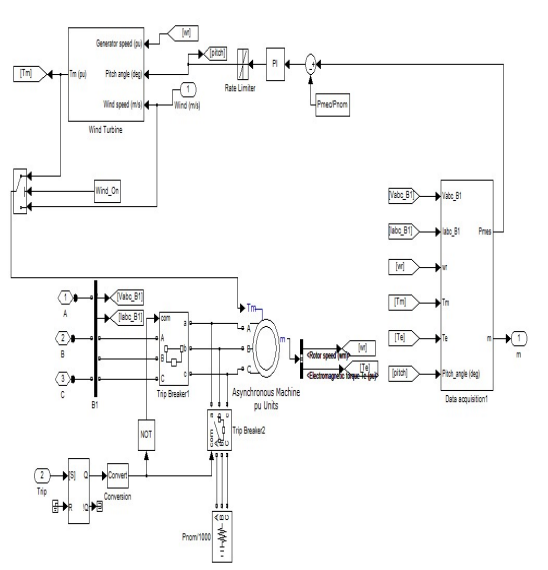

(a)

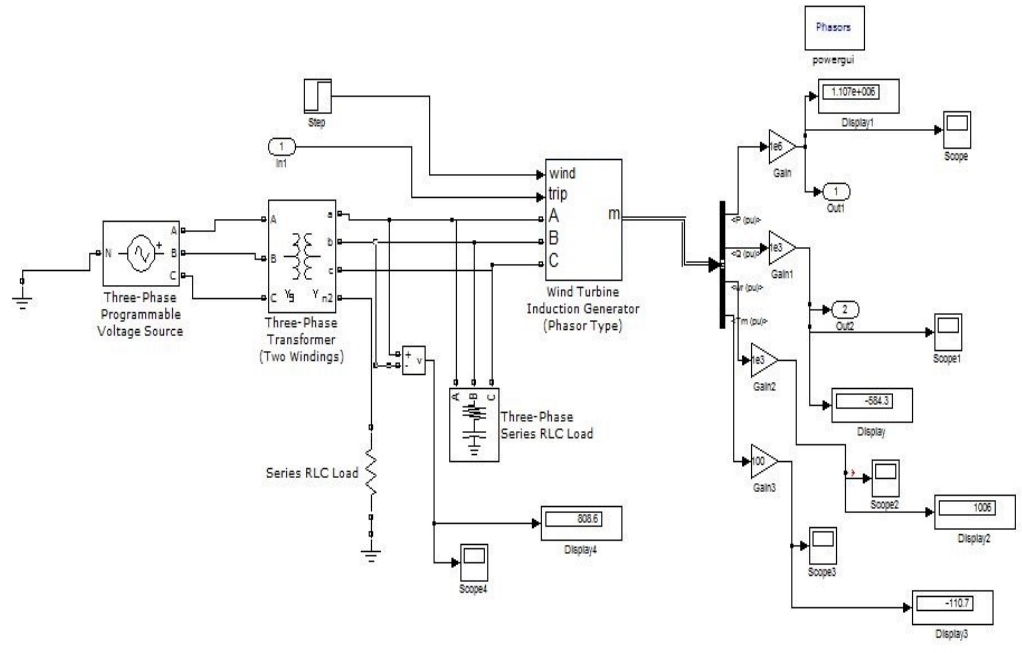

(b)

Figure 3. (a). Block diagram of the wind turbine and the squirrel cage generator. (b) Block diagram of the wind chain driven by a squirrel cage generator $\left(1^{\text {st }}\right.$ chain $)$

The model of the Doubly-Fed Induction Generator (DFIG):

For the 3 phases of stator, we have the same condensed matrix (1), and for the 3 phases of rotor, we have:

$$
\left[\mathrm{V}_{\mathrm{rabc}}\right]=\left[\mathrm{R}_{\mathrm{r}}\right] *\left[\mathrm{i}_{\mathrm{rabs}}\right]+\frac{\mathrm{d}}{\mathrm{dt}}\left[\emptyset_{\mathrm{rabc}}\right] \quad(\neq 0)
$$

After the Three phase two-phase transformation (Park), we get the following components along the axis $\mathrm{d}$ and q axis, for the stator voltages:

$$
v_{\mathrm{d} s}=R_{s} i_{d s}+\frac{d}{d t} \emptyset \mathrm{d} s-\omega s \emptyset q s
$$

Volume 9 Issue 2 December 2017 
And for the rotor voltages:

$$
v_{\mathrm{qs}}=\mathrm{R}_{\mathrm{s}} \mathrm{i}_{\mathrm{qs}}+\frac{\mathrm{d}}{\mathrm{dt}} \phi \mathrm{qs}+\omega s \phi \mathrm{ds}
$$

$$
\begin{aligned}
& v_{\mathrm{dr}}=\mathrm{R}_{\mathrm{r}^{1} \mathrm{dr}}+\frac{\mathrm{d}}{\mathrm{dt}} \phi \mathrm{dr}-\omega \mathrm{r} \phi \mathrm{qr} \\
& v_{\mathrm{qs}}=\mathrm{R}_{\mathrm{r}} \mathrm{i}_{\mathrm{qr}}+\frac{\mathrm{d}}{\mathrm{dt}} \phi \mathrm{qr}+\omega \mathrm{wr} \phi \mathrm{dr}
\end{aligned}
$$

To adequately control the electricity production of the wind, we will achieve independent control of active and reactive powers Ps and Qs stator [1] [2], [3], [4], [5], [6]. The reference (dq) is oriented so that

$$
\emptyset \mathrm{ds}=\emptyset_{\mathrm{s}} \text { And } \emptyset \mathrm{qs}=0
$$

Assuming that the stator flux os is constant (constant electric network) and ignoring the stator resistance we obtained for Ps (stator active power), Qs (stator reactive power) and $\mathrm{C}_{\mathrm{em}}$ (electromagnetic torque):

$$
\begin{aligned}
& P s=-V s \frac{M}{L s} i_{\text {igr }} \\
& \mathrm{Qs}=-\mathrm{Vs} \frac{\mathrm{M}}{\mathrm{Ls}} \mathrm{i}_{\mathrm{dr}}+\frac{\mathrm{Wg}^{2}}{\mathrm{~L}_{\mathrm{s}} \mathrm{w}_{\mathrm{s}}} \\
& \mathrm{C}_{\mathrm{em}}=-\mathrm{p} \frac{\mathrm{MI}}{\mathrm{L}_{\mathrm{s}}} \emptyset_{\mathrm{ds}} \mathrm{i}_{\mathrm{qI}},(\mathrm{p} \text { : Number of pairs of poles) } \\
& \Theta_{d s}=L_{s} i_{d s}+M i_{d r} \\
& \phi_{\mathrm{qs} s}=\mathrm{L}_{\mathrm{s}} \mathrm{i}_{\mathrm{qs} s}+\mathrm{Mi}_{\mathrm{qr}} \\
& \emptyset_{\mathrm{dr}}=\mathrm{L}_{\mathrm{T}} \mathrm{i}_{\mathrm{dr}}+\mathrm{Mi}_{\mathrm{dg}} \\
& \emptyset_{\mathrm{dr}}=\mathrm{L}_{\mathrm{r}} \mathrm{i}_{\mathrm{qqr}}+\mathrm{Mi}_{\mathrm{qqs}} \\
& \mathrm{Ls}=1 \mathrm{~s}-\mathrm{Ms} ; \mathrm{Lr}=1 \mathrm{r}-\mathrm{Mr}
\end{aligned}
$$

Ls and Lr are cyclical inductance of a stator phase and rotor phase.

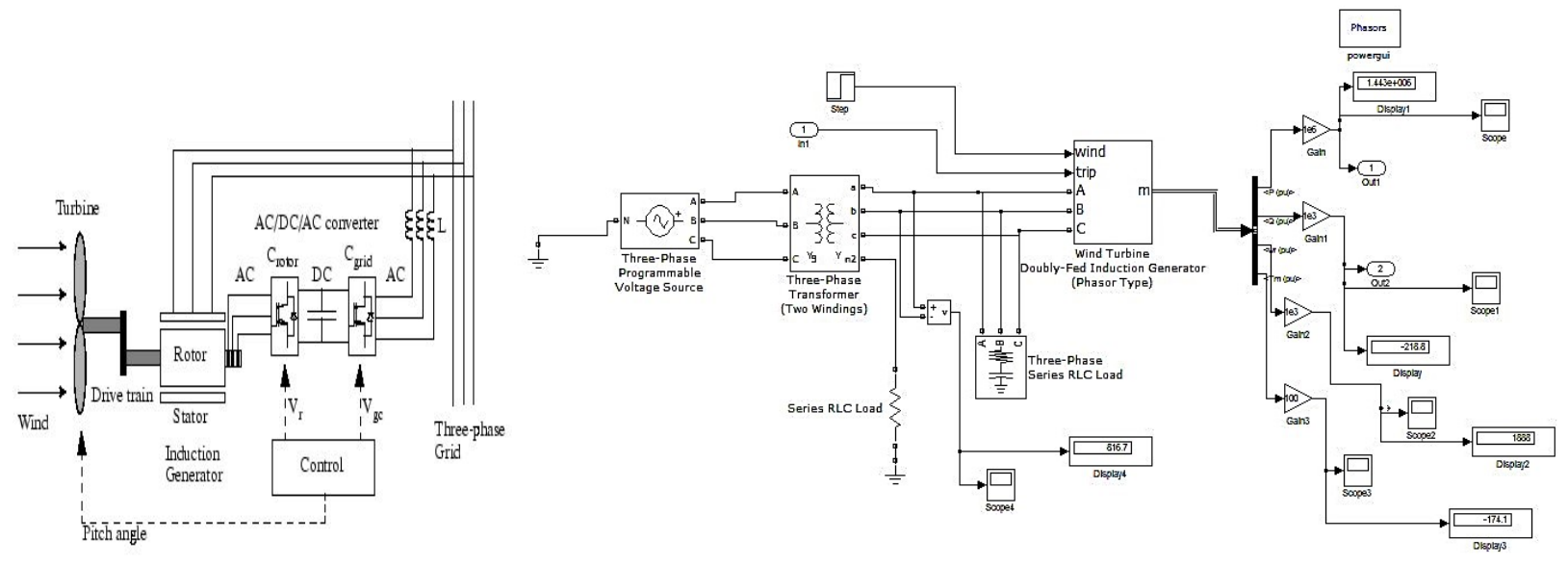

(a)

(b)

Figure 4. (a) Principle of operation of the wind turbine and the Doubly-Fed Induction Generator (b) Block diagram of a Wind chain driven by a DFIG $\left(2^{\text {nd }}\right.$ chain $)$

Simulation parameters-

The characteristics of the wind energy conversion systems are given in the following tables:

Table -1 Characteristics of the $1^{\text {st }}$ wind chain

\begin{tabular}{|c|c|c|c|}
\hline $\begin{array}{c}\text { Wind turbine and the squirrel cage } \\
\text { generator } \\
\operatorname{Sn}(\mathrm{VA}), \mathrm{Vn}(\mathrm{Vrms}), \mathrm{fn}(\mathrm{Hz})]\end{array}$ & $1,5 \mathrm{e}^{6} \mathrm{VA}, 575 \mathrm{~V}, 50 \mathrm{~Hz}$ & Wind speed & $12 \mathrm{~m} / \mathrm{s}$ \\
\hline Rotor Résistance & $\mathbf{0 . 0 0 4 4} \Omega$ & Number of pairs of poles & 3 \\
\hline Rotor Inductance & $\mathbf{0 . 1 7 9} \mathrm{H}$ & Stator Résistance & $\mathbf{0 . 0 0 4 8} \Omega$ \\
\hline Mutual inductance & $\mathbf{6 , 7 7 \mathrm { H }}$ & Stator Inductance & $0.1248 \mathrm{H}$ \\
\hline Balanced three-phase Load & $575 \mathrm{~V}, 4.10^{5} \mathrm{~W},-4.10^{5} \mathrm{VAR}$ & Transformer & {$[25 \mathrm{e} \mathrm{V}, 575 \mathrm{~V}]$} \\
\hline
\end{tabular}

Table -2 Characteristics of the $2^{\text {nd }}$ wind chain 


\begin{tabular}{|c|c|c|c|}
\hline $\begin{array}{c}\text { Wind turbine and the DFIG } \\
\text { Sn(VA), Vn(Vrms), fn(Hz)] }\end{array}$ & $1,5 \mathrm{e}^{6} \mathrm{VA}, 575 \mathrm{~V}, 50 \mathrm{~Hz}$ & Wind speed & $12 \mathrm{~m} / \mathrm{s}$ \\
\hline Rotor Résistance & $0.0048 \Omega$ & Number of pairs of poles & 3 \\
\hline Rotor Inductance & $0.179 \mathrm{H}$ & Stator Résistance & $\mathbf{0 . 0 0 4 8} \Omega$ \\
\hline Mutual inductance & $\mathbf{6 , 7 7} \mathrm{H}$ & Stator Inductance & $0.1248 \mathrm{H}$ \\
\hline Balanced three-phase Load & $575 \mathrm{~V}, 4.10^{5} \mathrm{~W},-4.10^{5} \mathrm{VAR}$ & Transformer & {$[25 \mathrm{e} \mathrm{V}, 575 \mathrm{~V}]$} \\
\hline
\end{tabular}

\section{TESTS AND RESULTS}

Power coefficient and mechanical torque supplied by the turbine-

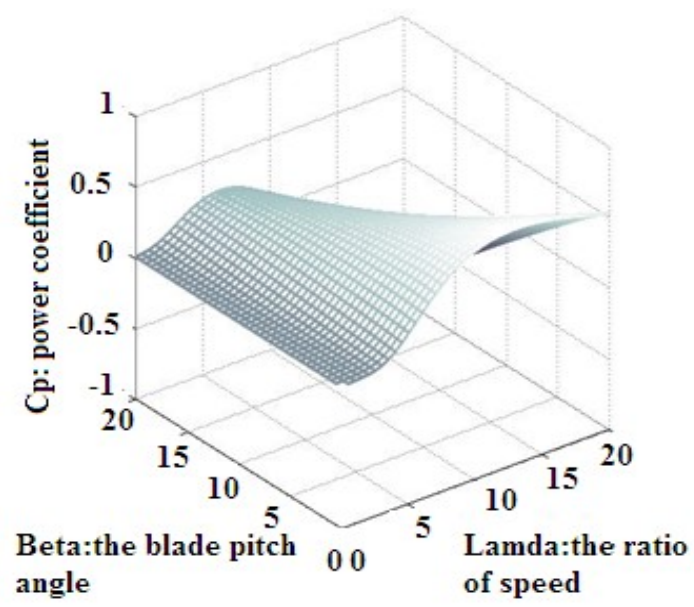

(a)

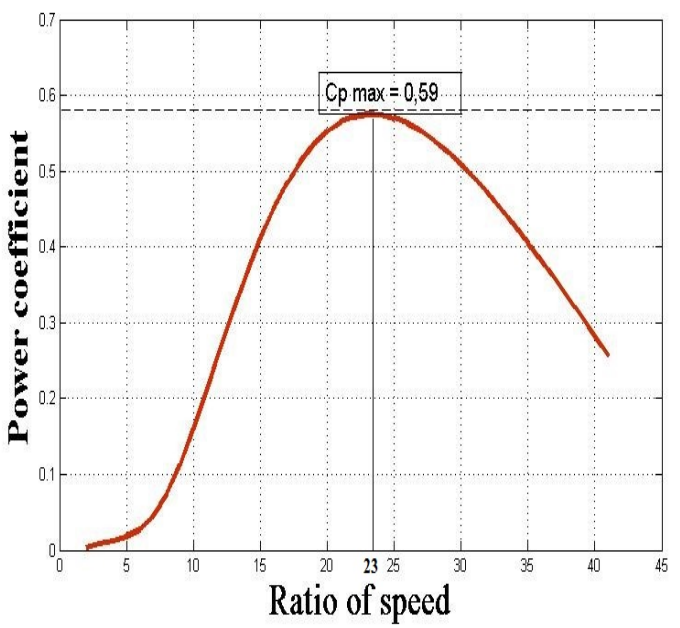

(b)

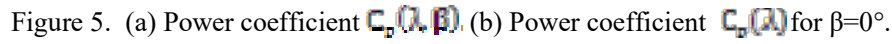

This turbine will have a maximum yield $\mathbf{C}_{\mathrm{p}}=0,59$ for a speed ratio $\lambda$ of the order of 23 (since in general, $\mathrm{C}_{\mathbf{p}}$ is maximum for $\beta=0^{\circ}$ ).

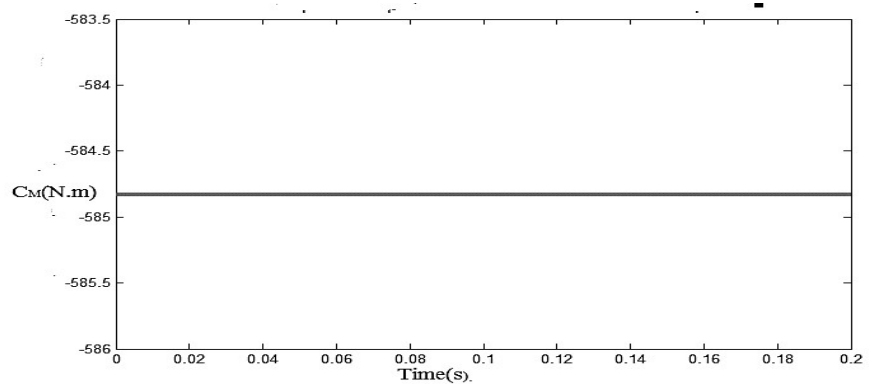

Figue 6. Mecanical torque

We used the technique "Stall control"(see figure 2). It is a passive technique that allows a natural aerodynamic stall. We got a constant torque at the exit of the turbine. the model of the simulated turbine is well suited to the conversion of wind energy.

Active power supplied to the load- 


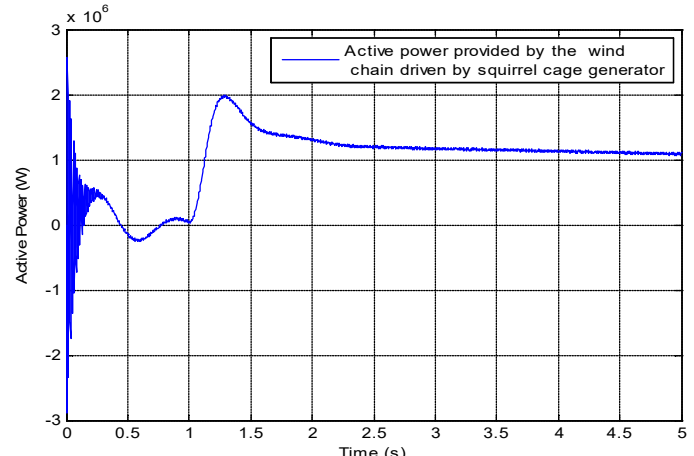

(a)

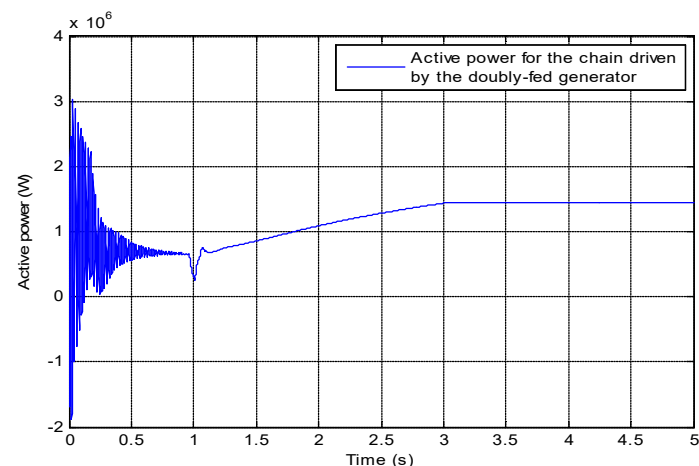

(b)

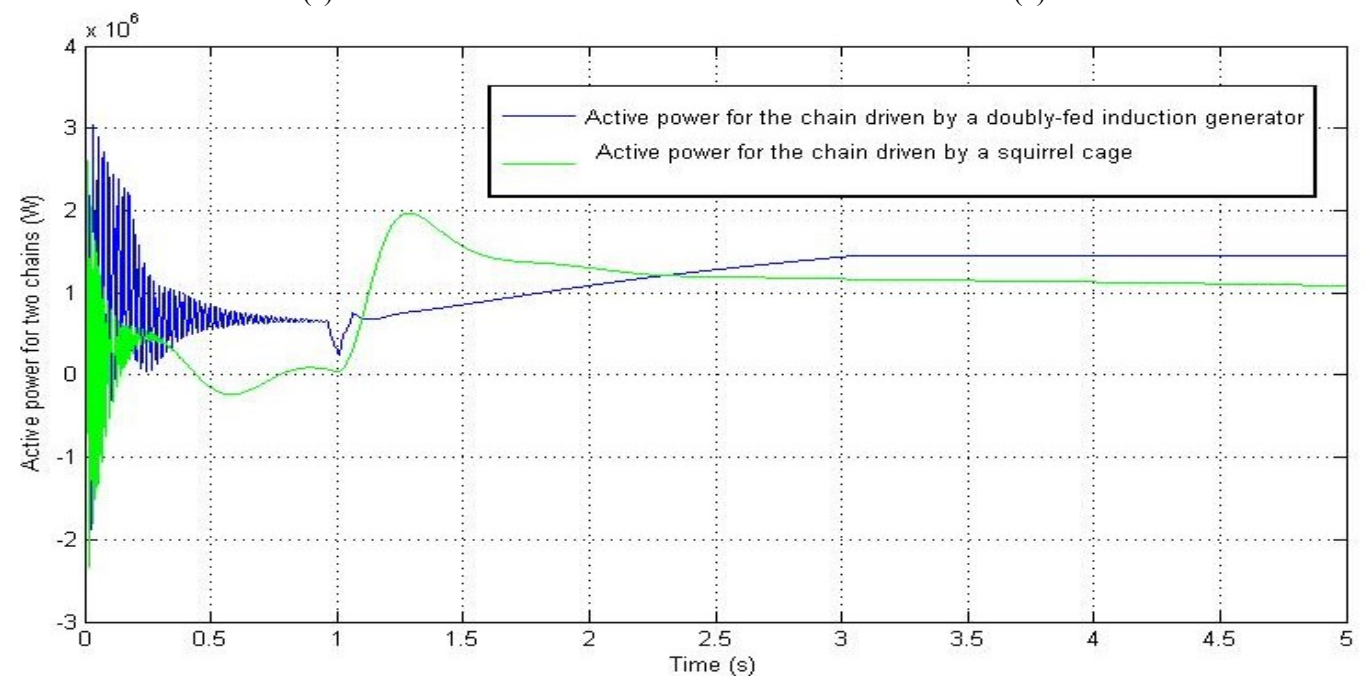

(c)

Figure 7. (a) Active power supplied by the first chain. (b) by the second chain. (c) by both chains. Reactive power supplied to the load-

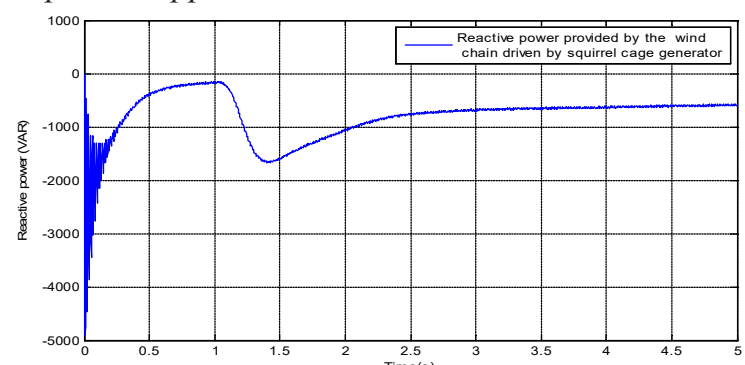

(a)

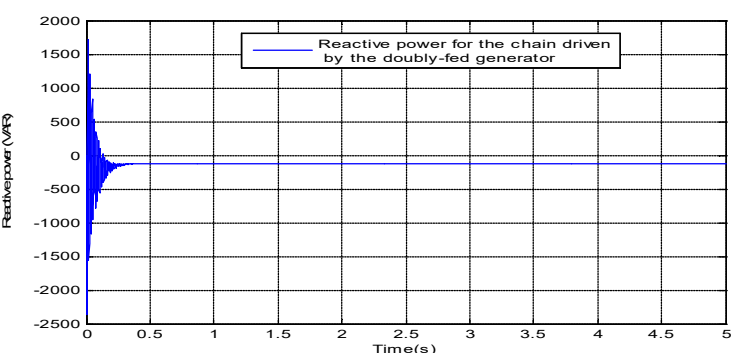

(b)

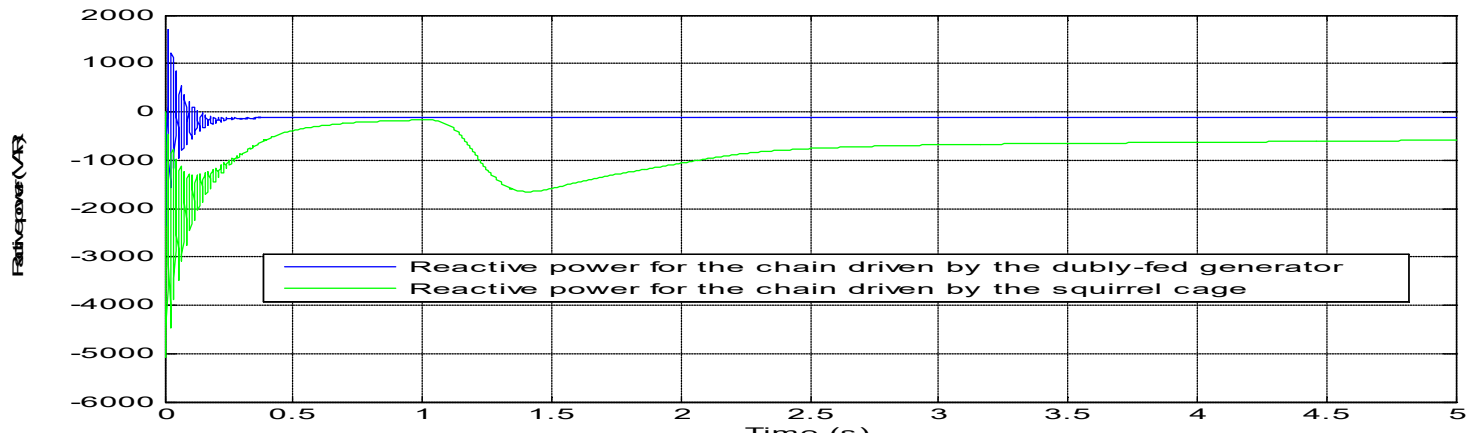

(c)

Figure 8. (a) Reactive power supplied by the first chain. (b) by the second chain. (c) by both chains. 
Electromecanical torque and rotation speed-

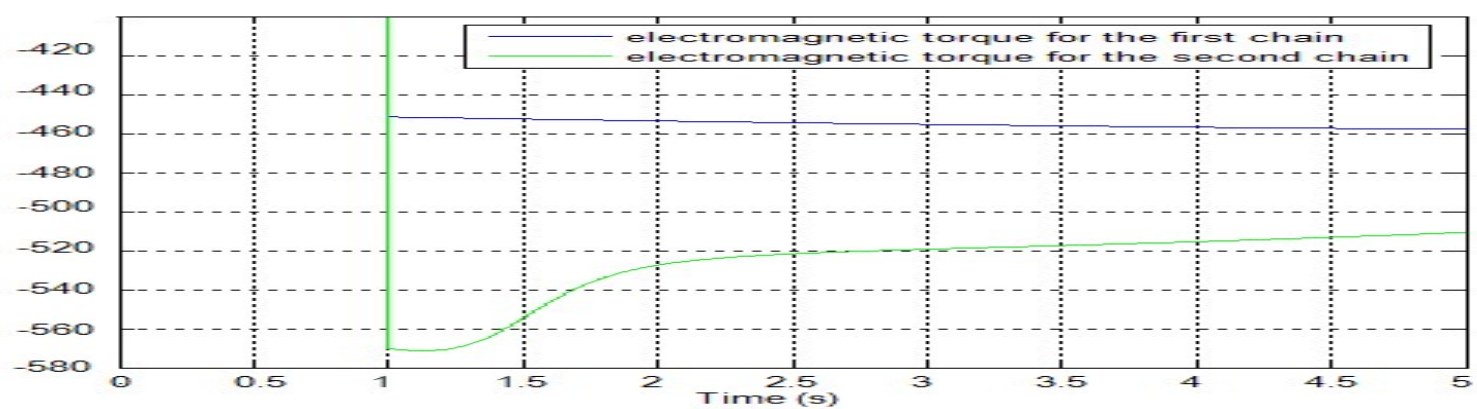

Figure9. Electromagnetic torque (N.m) for the two chains

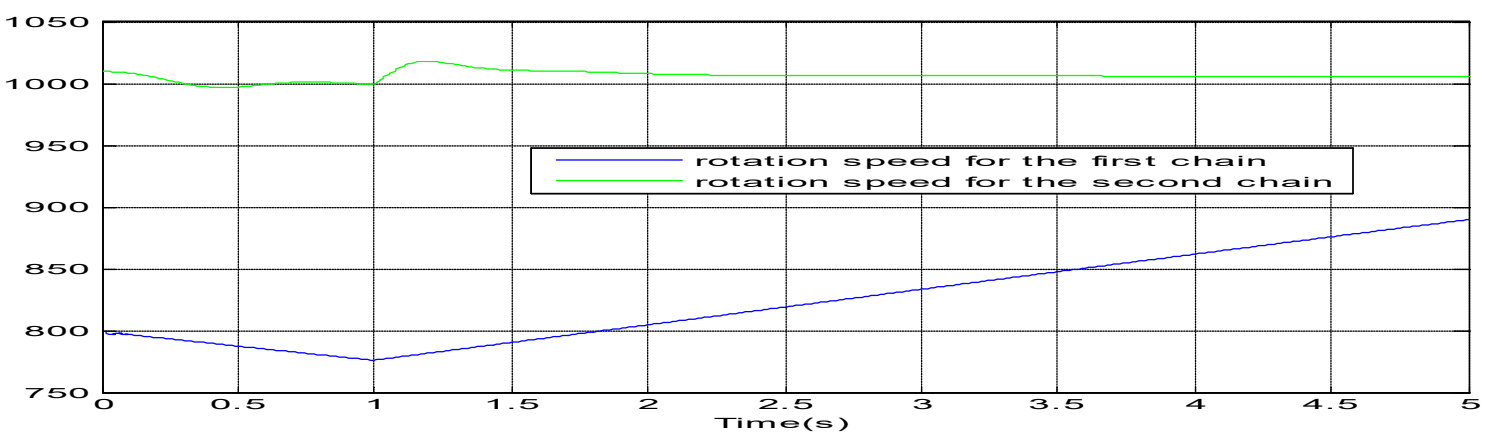

Figure 10. Rotation speed (in rotation per minute) for the two chains

The effective value of the stator voltage -

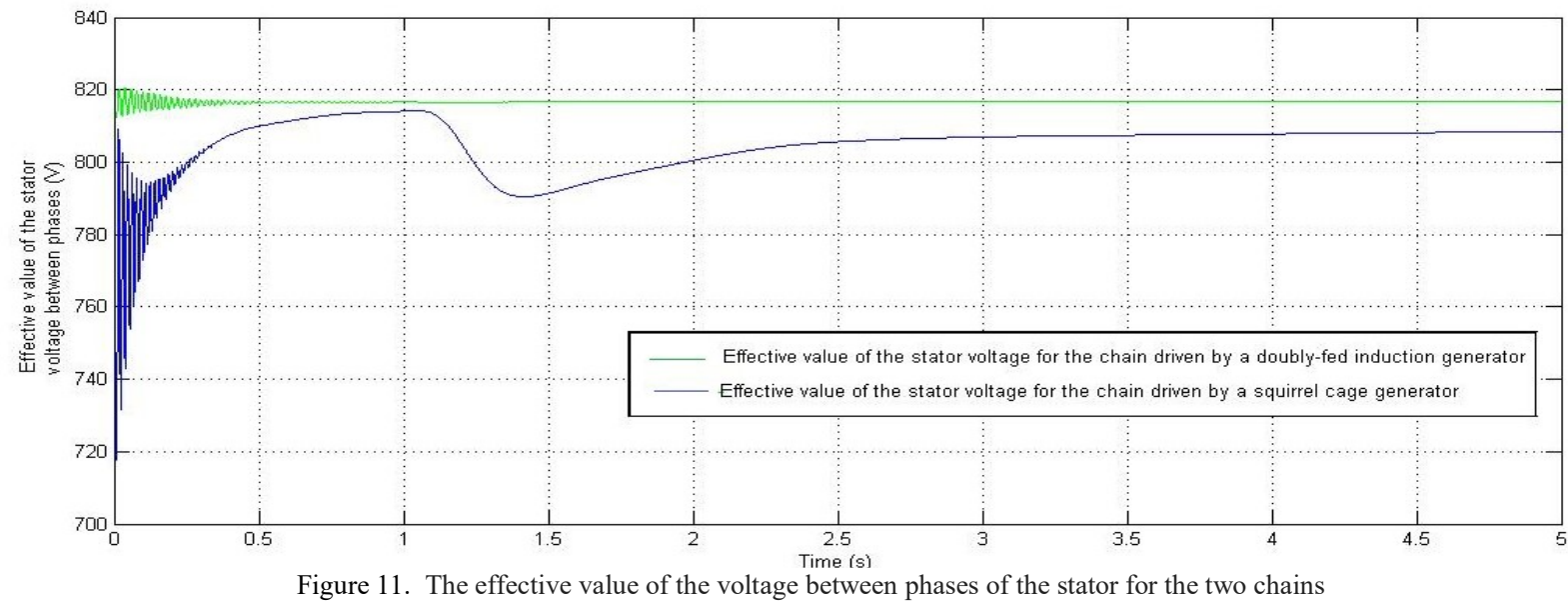

Comments and discussions-

In this paragraph, we will try to compare the simulation results of the two wind energy conversion channels whose components are identical (see Table 1 and Table 2), but the electric generator is different : the first one is a squirrel cage generator and the second is a doubly-fed induction generator. These two electric generators have the same nominal parameters: same active power, same nominal voltage and same frequency, all in order to make a good comparison of the performances of each wind turbine chain.

We find that the two channels work properly: they provide the load (here an R-C load), a relatively large electrical power. We note that both channels go through a transitional period of almost 3 seconds.

The steady state allowed us to make a good comparison of the two wind chains, for this we have grouped in $3^{\text {th }}$ table, the values measured in steady state of the following quantities: P (active power), Q (reactive power), Us (effective value of stator voltage between phases), Cem (electromagnetic torque)and N ( rotation speed). 
Table 3- Final values of the variables measured for both wind chains

\begin{tabular}{|c|c|c|c|c|c|}
\hline & Active power & $\begin{array}{l}\text { Reactive } \\
\text { power }\end{array}$ & $\begin{array}{l}\text { Effective value of } \\
\text { stator voltage }\end{array}$ & Electromagnetic torque & $\begin{array}{l}\text { Rotation } \\
\text { speed }\end{array}$ \\
\hline $\begin{array}{l}1^{\text {st }} \text { Chain } \\
\text { (With an squirrel } \\
\text { cage machine) }\end{array}$ & $P=1,1.10^{6} W$ & $Q=-600 \mathrm{VAR}$ & $\mathrm{Us}=804 \mathrm{~V}$ & Cem $=-458 \mathrm{Nm}$ & $\begin{array}{l}\mathrm{N}=890 \\
\text { rotations/mn }\end{array}$ \\
\hline $\begin{array}{l}2^{\text {nd }} \text { Chain } \\
\text { (With a doubly-fed } \\
\text { induction generator) }\end{array}$ & $P=1,4.10^{6} W$ & $Q=-100 V A R$ & $\mathrm{Us}=\mathbf{8 1 3 \mathrm { V }}$ & Cem $=-510 \mathrm{Nm}$ & $\begin{array}{l}\mathrm{N}=1010 \\
\text { rotations/mn }\end{array}$ \\
\hline
\end{tabular}

The third table shows that:

- The active power supplied to the load (R-C) is more important for the second chain: more than $27 \%$.

-The difference between the reactive powers for the two output chains is obvious: the second channel with a DFIG has a reactive power of almost zero.

- The voltage between the phases of the stator is almost identical for the two chains.

- The second chain provides more torque than the first: more than $11 \%$.

- The speed of rotation is almost identical, but we notice that in the $2^{\text {nd }}$ chain it is close to the speed of synchronism.

The generator works in a hyper-synchronous diet which is not possible with a squirrel cage machine.

\section{IV.CONCLUSION}

All the quantities are almost stable in steady state, which shows that the two systems work properly, We note, for this power range, that the second chain works best: the power delivered to the load is higher, this is because in the case of DFIG the generator restores the active power load: $\mathrm{Pr}$ (rotor power) $=\mathrm{g} * \mathrm{P}(\mathrm{P}$ active power at the stator, $\mathrm{g}$ is the slip).

As for the reactive power that is zero for the second channel, we can say that the charge capacitors compensate the energy involved in the system which does not occur with the first channel. The developed pair is higher in the case of the 2 nd chain.

We conclude that for this power range, the second string works best.

This study shows the interest of using a DFIG for the production of wind energy for medium and high power chains.

\section{REFERENCES}

[1] F. Poitiers, " Etude et commande de génératrices asynchrones pour l'utilisation de l'énergie éolienne ", Ph.D. thesis, univ. Nantes, 2003.

[2] A. Boyette, "Controlling a doubly-fed asynchronous generator with storage system," Ph.D. thesis, university Poincaré, Nancy, 2006.

[3] A. El Moudden, A. Wahabi, A.Sandali, F.E Bounifli, " Control and optimization of the energy produced by a chain of wind energy conversioncontrolled by a doubly-fed asynchronous generator ", in CTTS, Vol. 3, 2014.

[4] A. Wahabi, A. El Moudden, A. Sandali, F. E. Bounifli. "Improved performance of a Wind Energy Conversion Chain Driven by an Asynchronous Generator Doubly-Fed and using a «R-L » Filter”. In IJCCE April, Vol. 6, 2015.

[5] A. Wahabi, A. El Moudden, A. Sandali, F. E. Bounifli, "Modelling and simulation of a double-fed asynchronous generator for control of wind energy", International Congress of Thermal, Agadir, Maroc, April 2014.

[6] S. Khojet El Khil, Vector control of a doubly fed induction machine (DFIG) / Optimization losses in the converters, 2006J.

[7] A. Tamaarat, "Modélisation et commande d'un système de conversuion d'énergie éolienne à base d'une MADA", Ph.D. thesis, univ. Biskra Algeria. 